FIGUEIREDO, Francisco José Quaresma de. Vygotsky: a interação no ensino/aprendizagem de línguas. São Paulo: Parábola, 2019. 125p.

ISBN: 978-85-7934-159-5

\title{
PROCESSOS DE ENSINO E APRENDIZAGEM DE LÍNGUAS SOB A ÓTICA DA TEORIA SOCIOCULTURAL
}

\section{LANGUAGE TEACHING AND LEARNING PROCESSES IN LIGHT OF THE SOCIOCULTURAL THEORY}

Aline Dubal Machado ${ }^{1}$, Augusto Weiand ${ }^{2}$, Francieli Motter Ludovico ${ }^{3}$, Patrícia da Silva Campelo Costa Barcellos ${ }^{4}$

Vygotsky: a interação no ensino/aprendizagem de línguas é um livro resultado do estágio pós-doutoral de Francisco José Quarentena de Figueiredo, que tem como objetivo explanar as principais contribuições da Teoria Sociocultural (TS) de Vygotsky e seus colaboradores. O autor possui doutorado e pós-doutorado em Linguística Aplicada e é docente da Faculdade de Letras da Universidade de Goiás (UFG). Pesquisa, principalmente, os seguintes temas: erro e correção, processo de escrita, aprendizagem colaborativa, telecolaboração e questões interculturais na aprendizagem de línguas.

A obra está dividida em seis capítulos, com 125 páginas, onde é apresentada uma discussão teórica acerca da TS e suas aplicações nos processos de ensino e aprendizagem de línguas. Figueiredo afirma que "esta obra decorre da minha paixão por Vygotsky e por sua generalidade em enfatizar que a interação favorece a aprendizagem e o desenvolvimento cognitivo dos seres humanos" (p. 10).

\footnotetext{
${ }^{1}$ Doutoranda em Informática na Educação na Universidade Federal do Rio Grande do Sul - UFRGS; Mestre em Distúrbios da Comunicação Humana; Graduada em Educação Especial. Professora de Língua Brasileira de Sinais do Instituto Federal de Educação, Ciência e Tecnologia do Rio Grande do Sul - IFRS. Campus Osório.

${ }^{2}$ Doutorando em Informática na Educação na Universidade Federal do Rio Grande do Sul - UFRGS; Mestre em Ciência da Computação; Licenciado em Informática. Técnico do Instituto Federal de Educação, Ciência e Tecnologia do Rio Grande do Sul - IFRS. Campus Osório.

${ }^{3}$ Doutoranda em Informática na Educação na Universidade Federal do Rio Grande do Sul - UFRGS; Mestre em Letras; Graduada em Letras Licenciatura- Português/Inglês. Professora da Universidade Tecnológica Federal do Paraná - UTFPR Campus Dois Vizinhos.

${ }^{4}$ Doutora em Informática na Educação e em Linguística Aplicada; Mestre em Letras; Graduada em Letras LicenciaturaPortuguês/ Inglês. Professora do Programa de Pós-Graduação em Informática na Educação e do Instituto de Letras Universidade Federal do Rio Grande do Sul - UFRGS.
} 
No capítulo Vygotsky e a sua Teoria, Figueiredo, primeiramente, fala sobre Vygotsky, sua breve vida, formação e estudos envolvendo psicologia, baseando-se sobretudo nas teorias behaviorista e na psicologia de Gestalt. $\mathrm{O}$ autor faz menção a um trecho do texto de Cole e Scribner (1998, p. 7 apud FIGUEIREDO, 2019, p. 12), o qual descreve como Vygotsky buscava uma nova abordagem que o satisfizesse - "uma abordagem abrangente que possibilitasse a descrição e a explicação das funções psicológicas superiores em termos aceitáveis às ciências naturais". A discussão continua no entorno da metodologia e dos princípios do materialismo dialético trazidos por Vygotsky para a solução de problemas. Sob essa questão, é descrito o método genético que ele desenvolve em seu trabalho. Figueiredo também traz referências da fundamentação nos trabalhos de Marx e Engels para o desenvolvimento da teoria de Vygotsky, reforçando o importante esquema teórico construído por ele, relativo ao desenvolvimento cognitivo dos seres humanos.

Prosseguindo, Figueiredo apresenta a TS de Vygotsky, que era praticamente desconhecida desde sua morte até aproximadamente os anos 1970, em virtude das circunstâncias políticas repressivas da antiga União Soviética. $\mathrm{Na}$ sequência, há uma discussão sobre as diferenças entre a TS e a teoria de Piaget, visto que a TS centra-se nas questões culturais, de interação social e dimensão histórica. Piaget, por sua vez, enfatiza os processos biológicos do desenvolvimento.

O autor ainda aborda a Teoria da Atividade e a relaciona com a TS de Vygotsky, assim ampara-se em demais estudiosos para defini-la e traz exemplos referentes à aprendizagem de L2 (Segunda Língua)/LE (Língua Estrangeira). Dentre os autores, Figueiredo cita Miccoli (2013, p. 73 apud FIGUEIREDO, 2019, p. 20), a qual explica que "qualquer iniciativa humana se constitui em atividade num enquadre que envolve motivo, meta e operações em sua consecução - motivo relacionado à necessidade que motiva a ação; meta como objetivo a alcançar; e operações, à maneira e às condições contextuais". Figueiredo ratifica princípios fundamentais da TS para finalizar o capítulo, descrevendo sobre o papel do homem como sujeito interativo e a apropriação de seu conhecimento nas relações através da linguagem.

O segundo capítulo, intitulado As Falas Egocêntrica, Interior e Privada, aborda a importância do diálogo no desenvolvimento cognitivo de indivíduos. Com isso, Figueiredo demonstra a relevância dessas falas na TS, essenciais para a criança tanto nas interações quanto para seu desenvolvimento. 
A fala egocêntrica, conforme Vygotsky, representaria uma transição entre as funções intermentais e intramentais. Complementando, Figueiredo apresenta, de acordo com a TS, os três estágios de desenvolvimento cognitivo por que a criança passa: regulação pelo objeto, regulação pelo outro e autorregulação. A criança usa a fala para objetivos comunicativos, como também para guiar, planejar e monitorar suas ações, seu comportamento de maneira autorregulada, usando a fala privada ou interior (DIAZ et al., 1992; PELLEGRINI, 1981 apud FIGUEIREDO, 2019). Em ambas, a criança fala consigo mesma, mas a fala interior refere-se a um processo durante o qual a criança não externaliza enunciados linguísticos. Figueiredo ilustra através de diversos exemplos os três tipos de falas apresentadas por Vygotsky e discutidas neste capítulo, associadas tanto ao aprendizado de L2/LE quanto à linguagem dos surdos.

No caso especificamente dos surdos, Vygotsky defendia que esses fossem incluídos em um sistema escolar juntamente com pessoas ouvintes, bem como tivessem acesso à língua de sinais como os ouvintes têm às línguas orais. Figueiredo, assim, descreve a ótica de Vygotsky sobre a educação bilíngue e a educação inclusiva para a comunidade surda. $\mathrm{O}$ autor da TS era contra a segregação e reconhecia a educação inclusiva como a mais benéfica para as pessoas com deficiência, pois teriam a oportunidade de desenvolvimento a partir das interações sociais.

Figueiredo descreve acerca da educação dos surdos no Brasil, enfatizando a falta de tradutores/intérpretes de Libras/Língua Portuguesa para cumprir a demanda existente nas instituições de ensino, apesar da existência do Decreto Federal $n^{0}$ 5.626/05 que institui a Libras como disciplina curricular obrigatória nos cursos de licenciatura e optativa nos cursos de bacharelado, objetivando o público universitário a ter contato com a Libras e a cultura surda. Ele ainda faz uma crítica ao sistema educacional, pois embora a educação inclusiva para surdos tenha respaldo legal, ainda há privações de acesso educacional em comparação àquele existente para os ouvintes, visto que não lhes é garantida a interação com os demais no âmbito educacional.

No capítulo A Mediação e a ZDP (Zona de Desenvolvimento Proximal), Figueiredo apresenta-nos os conceitos fundamentais que norteiam a TS e aponta como esses ocorrem diante do uso das tecnologias, trazendo um olhar atual com diferentes formas de compreensão e uso desses termos na área de ensino e aprendizagem de L2/LE e educação. 
Figueiredo conceitua mediação apoiada em diversos autores, considerando que toda relação é mediada. Descreve pressupostos de Vygotsky sobre a criação de instrumentos, pois o homem os cria e os adapta, segundo a necessidade do mundo exterior. Assim, Figueiredo, de acordo com Vygotsky, aborda a noção de mediação instrumental, dado que no percurso da história e por meio dos artefatos culturais o homem desenvolveu diversos instrumentos para mediar sua sobrevivência, os quais também influenciaram seus processos de aprendizagem. Dessa forma, a mediação é o aspecto central da TS de Vygotsky.

Dando continuidade, o autor descreve a diferença entre instrumento técnico e psicológico, lembrando que os instrumentos têm a função de regular, controlar ou mudar as ações sobre o objeto no contexto externo. Compreende-se, por exemplo, como instrumento técnico o computador, smartphone, livros, dicionários, etc. Por sua vez, os instrumentos psicológicos referem-se aos signos, como, por exemplo, a linguagem. Com isso, a fala tem função mediadora entre os homens, contribuindo nas relações sociais e cumprimento de tarefas. Logo, a função mediadora da língua ou outros sistemas simbólicos exerce a mediação semiótica (COLAÇO et al., 2007; MAHN, 1999 apud FIGUEIREDO, 2019, p. 39).

Nesse sentido, ao investigar a obra de Vygotsky, Karpov e Haywood (1998 apud FIGUEIREDO, 2019) identificam e descrevem dois tipos de mediação: a metacognitiva e a cognitiva. A primeira compete ao processo de aquisição pela criança em relação aos instrumentos semióticos de autorregulação. Já a segunda diz respeito à aquisição de ferramentas cognitivas fundamentais para resolver problemas. Somando-se a ela tem-se a mediação cognitiva sistematizada, a qual inicia-se com o processo de aprendizagem escolar, a partir dos conceitos científicos.

Conforme Figueiredo, para Vygotsky os meios de interação entre os homens transformaram-se desde a antiguidade até a atualidade, assim como os meios de aprendizagem. O autor, amparado em Fett e Nébias (2005 apud FIGUEIREDO, 2019), assinala que a tecnologia é um fenômeno que auxilia na transformação da vida dos homens, pois influencia no trabalho, nas relações sociais e culturais, no modo de pensar, no entretenimento, bem como nos processos de ensino e aprendizado. Ainda, neste contexto, considera-se que a tecnologia e o homem podem ser dependentes, visto que essa é o resultado da própria ação histórica e cultural deste homem em sociedade.

Para o autor desta obra, a teoria vygotskiana ratifica a necessidade de a criança perpassar pelos estágios de desenvolvimento cognitivo e emocional. Esses estão atrelados às 
interações sociais, as quais devem ocorrer tanto com crianças mais experientes quanto com adultos. Para isso, a interação assistida é primordial, pois auxiliará no desenvolvimento das funções psicológicas superiores. Neste processo, as interações assistidas e mediadas são evidenciadas na definição de ZDP, a qual representa a distância entre o que uma criança/um aprendiz pode realizar individualmente e o que ela/ele pode produzir com o auxílio de um adulto/indivíduo mais competente.

Figueiredo faz uma relevante discussão sobre ZDP, utilizando diferentes autores e exemplos, bem como apresentando um mapa conceitual ilustrativo do ciclo do processo que ocorre durante a ZDP. Contribuindo com está análise, Figueiredo conceitua internalização e enfatiza o processo interpessoal e intrapessoal como essenciais na teoria de Vygotsky. Ainda neste capítulo, o autor retoma a importância da interação social e o trabalho colaborativo, ressaltando o papel do expert e introduzindo o termo scaffolding.

No capítulo A Metáfora do Scaffolding, Figueiredo situa a origem do termo, que foi cunhado por Wood, Bruner e Ross (1976 apud FIGUEIREDO, 2019). Scaffolding, em português, significa andaimento ou andaime. O autor situa andaimento e ZDP no decorrer desta sequência de definições trazidas pela TS e exemplifica o papel do adulto ou criança mais experiente no processo de desenvolvimento e aprendizagem do outro menos experiente, assim pontuando esse processo na ZDP por meio do andaime. Apresenta ilustrações indicando a Zona de Desenvolvimento Proximal e a construção que ocorre no aprendiz quando se apoia em andaimes até fazer algo de forma independente, ou seja, até a autorregulação.

Em seguida, são apresentadas seis funções do indivíduo mais experiente (tutor) no processo de scaffolding, que, segundo Wood, Bruner e Ross (1976 apud FIGUEIREDO, 2019), é aquele capaz de engajar o aprendiz na tarefa, simplificá-la, manter a motivação do aprendiz, identificar pontos importantes para a realização da tarefa, reduzir o estresse do aprendiz, explicar e dar soluções parciais para finalização da tarefa. O capítulo também traz exemplos para descrever o uso dessas funções e indica que o scaffolding deve ser realizado com base dialógica e, assim, estruturar-se a ZDP.

Para o autor, scaffolding caracteriza-se pelo diálogo instrumental, através de um apoio dado a uma pessoa para fazer determinada ação, tarefa e, no aprendizado de uma língua, para isso pode-se auxiliar o scaffolding, a partir de artefatos como ferramentas tecnológicas, mapas, livros, etc. Desta forma, com base em diversos autores, Figueiredo descreve algumas estratégias mediadoras para o scaffolding, tais como: o uso da L1 (Primeira Língua) como 
forma de favorecer a realização da tarefa e de mediar os processos de ensino e aprendizagem de L2/LE; o uso de ferramentas digitais como apoio ao aprendizado de línguas para os alunos.

Figueiredo, apoiado em Reiser (2004 apud FIGUEIREDO, 2019), apresenta dois mecanismos de scaffolding para explicar como desenvolve-se este processo: scaffolding estruturante e o problematizador. O estruturante refere-se ao ato de mostrar como se executa a ação para resolver um determinado problema ou tarefa. Já o problematizador compreende-se como o conjunto de questionamentos e de indicações/orientações para que o outro possa resolver a tarefa dada ou situação problema. Com base nesses conceitos o autor traz exemplos que ilustram o scaffolding e a construção colaborativa. Ele acrescenta que a assistência através do scaffolding pode ter a intenção apenas de resolver uma tarefa e não exatamente de estimular o aprendiz, por isso indica que os professores devem discutir formas de scaffolding efetivos durante interações colaborativas. Entretanto, considera que o aprendiz não é passivo ao ter assistência, visto que se trata de interação.

No capítulo Teoria Sociocultural e Aprendizagem de L2/LE, o autor explica a importância da interação no desenvolvimento cognitivo e, dessa forma, a instrução também é essencial, por possibilitar ao aprendiz caminhar na ZDP. Nesse sentido, destaca que a interação na sala de aula de LE oferece oportunidades de input (insumo) e output (produção).

A TS está muito presente na área de ensino e aprendizagem de LE, a partir da qual o aprendiz é visto como ativo na construção do conhecimento e a aprendizagem de uma língua é entendida como prática social. Assim, Figueiredo traz discussões sobre a aplicação da TS nos processos de ensino e aprendizagem de LE e afirma que essa perspectiva tem influenciado tanto em contextos presenciais quanto em virtuais. Após essas considerações mais gerais, o autor apresenta reflexões sobre a TS levando em conta:

- Abordagem baseada em tarefas: a qual tem objetivo de propiciar contexto natural para produção linguística;

- Aprendizagem colaborativa de línguas: a qual foca na interação e colaboração na realização de trabalhos em grupos;

- O uso de jogos em sala de aula: voltado a motivar a interação dos estudantes na sala de aula;

- Avaliação dinâmica: a qual considera o processo de mudanças de aprendizagem através da intervenção dialógica entre estudante e professor; 
- Telecolaboração: a qual permite que alunos de diferentes instituições possam colaborar com a aprendizagem reciprocamente, o que possibilita o desenvolvimento de competências linguística-comunicativa e intercultural.

Em todos essas abordagens Figueiredo apresenta definições, traz discussões bibliográficas e exemplos por meio de suas próprias pesquisas, dentre outras, onde a TS é aplicada.

No último capítulo, A Teoria Sociocultural na Formação de Professores, Figueiredo expõe que apesar de Vygotsky não ter estudado essa questão diretamente, a TS também é aplicada ao desenvolvimento do professor. A perspectiva sociocultural, no contexto de formação de professores, é essencial para compreender como eles "pensam, aprendem e se comportam como agentes históricos sociais e políticos nos contextos de ensino e aprendizagem" (p. 95). Nesse sentido, a ZDP do professor pode ser desenvolvida a partir da interação entre alunos e professor, professor e coordenador, entre colegas, como também por meio de escrita de diários e narrativas, textos científicos, participação em eventos e projetos, etc.

$\mathrm{Na}$ sequência, o autor apresenta pesquisas realizadas com o intuito de exemplificar a análise da formação de professores por meio da TS, enfatizando a necessidade da colaboração e interação nesse processo. Assim, destaca as interações telecolaborativas, que por meio de recursos tecnológicos podem aprimorar os processos de ensino, aprendizagem e também de formação de professores, práticas que possibilitam o desenvolvimento de competência linguístico-comunicativa, intercultural e também profissional.

Nas Considerações Finais, Figueiredo ressalta que, apesar de sua breve vida, Vygotsky deixou muitas contribuições, as quais permitem afirmar a pertinência e utilidade da TS. Prossegue retomando algumas discussões e ideias do livro, destacando que a partir da TS compreende-se o sujeito como ativo e interativo, o qual constrói conhecimentos e se constitui a partir de suas relações inter- e intra- pessoais. Também sublinha a importância da instrução, interação, mediação e colaboração nos processos de ensino e aprendizagem de línguas.

Figueiredo reflete sobre a necessidade de mudanças na cultura da sala de aula e menciona o papel do professor, que deve buscar proporcionar um ambiente de aprendizagem onde os estudantes se engajem em atividades passíveis de gerar significativas interações e colaborações. 
A obra termina com a reflexão que a TS está em todo lugar, podendo ser percebida em qualquer interação colaborativa cujo objetivo é: "proporcionar crescimento humano, psicológico e intelectual" (p. 110), momento onde o autor convida seus leitores para continuar interagindo com Vygotsky.

Após a apresentação da obra de Figueiredo, busca-se tecer considerações e recomendações. O texto oferece uma leitura fluida e o autor expõe os conceitos da TS com clareza, além de apresentar exemplos, com outras pesquisas, associando a teoria à prática. Nesse sentido, tais escritos podem ser relevantes na iniciação da compreensão da teoria e de práticas de ensino e aprendizagem de LE/L2.

Por meio das articulações com outros autores, Figueiredo, ainda, nos oferece referências importantes para outras leituras. Traz significativas discussões para a teoria, buscando, através de exemplos, solucionar dúvidas entre termos da história da teoria em articulação com outros nomes importantes da área.

Sabe-se que são muitos os constructos das obras de Vygotsky, por isso talvez não houvesse oportunidade para desenvolver ainda mais o texto. Contudo, como sugestão para uma nova edição ampliada, caberia uma discussão mais aprofundada sobre a Teoria da Atividade e a Abordagem Baseada em Tarefas, visto que essas são questões muito examinadas nas pesquisas baseadas na TS.

As considerações da aplicação da TS ao contexto de ensino de Libras para surdos são significativas, pois Figueiredo pontua a relevância da educação inclusiva para surdos e demais deficientes e traz neste crivo a necessidade de se pensar como a educação ocorre entre os pares e a partir da colaboração com os mais experientes, o que gera possibilidades de aprendizagem. Essa reflexão contribui positivamente para o sistema educacional inclusivo. Seguindo nesta perspectiva, o autor, ao trazer sua contribuição sobre os testes de QI, mostra o olhar sobre os excluídos, visto que os testes não avaliam a partir da ZDP, ou seja, do que o sujeito sabe para o que ele alcançará através de possibilidades de mediação. O seu resultado já exclui possibilidades de andaimento e oferta de um ensino diferenciado.

Além das relações entre os pares serem benéficas, devido à interação e colaboração, as tecnologias também podem auxiliar a fomentar essas ações. As discussões do livro mostram a relevância da interação e colaboração nos processos de ensino e aprendizagem de línguas e na formação de professores. O autor aborda a questão dos instrumentos tecnológicos criados pelo homem e para o seu próprio uso, os quais surgem segundo as necessidades da sociedade. 
Esses são as ferramentas que servem de mediação instrumental e, atualmente, são utilizadas nas interações e colaborações em prol do processo de ensino e aprendizado de línguas e na educação em geral. Ou seja, fazendo uso apropriado, explorando as potencialidades das ferramentas digitais, as tecnologias podem servir de instrumentos mediadores para auxiliar nos processos de ensino e aprendizagem.

Desta maneira, esta obra é recomendada para quem tem interesse no pensamento vygotskiano e busca compreender os processos de ensino e aprendizagem de Língua Estrangeira/ Segunda Língua. Apesar de o livro de Figueiredo ser voltado mais especificamente à Linguística Aplicada, há uma inestimável contribuição para a educação como um todo, pois são oferecidos ricos exemplos sobre os processos de ensino e aprendizagem aplicados sob a ótica da Teoria Sociocultural. Apresentando uma leitura didática e envolvente, Vygotsky: a interação no ensino/aprendizagem de línguas é um livro de cabeceira para acadêmicos dedicados a explorar o legado vygotskiano na educação.

\section{Agradecimentos}

Agradecemos ao IFRS - Osório pela concessão de licença qualificação e horário especial de estudante para os autores Aline e Augusto, respectivamente. Agradecemos, também, a UTFPR - Dois Vizinhos pela concessão de licença capacitação para a autora Francieli. 